\title{
An Analysis of Reading Strategies Used by Ethiopian Higher Education Students: Evidence from Ambo University, Oromia, Ethiopia
}

\author{
Motuma Hirpassa Minda
}

Assistant Professor

Ambo University

College of Social Science and Humanities

Department of English Language and Literature

Ambo, Ethiopia

maldamercy@yahoo.com

\begin{abstract}
Concerned by increased problems about the students' reading quality, this study was carried out to investigate the reading approach of English major students of Ambo University. To achieve this objective, all 52(31 male and 21 female) English major students of the University were purposely selected for the study because the number of the students is small to manage. Both quantitative and qualitative data were obtained from the respondents through Reading Achievement Tests, Questionnaire and Structured Interview and analyzed accordingly. The study mainly focused on the students' approach to reading (adapted top- down or bottom-up) and the students' ability to identify the main ideas and details, explicitly stated and implied information, the purpose and the tone of authors in five different reading genres: dialogues, directions, article, essays, and poems. The overall result of the study showed that $89.7 \%$ of the University students were exclusively limited
\end{abstract}


to bottom-up approaches to reading and frustrated to determine the main ideas and implied information in the texts. In other words, no student answered more than $78 \%$ in reading comprehension items correctly in the tests. Moreover, half of the students could not answer above $50 \%$ in the comprehension questions. Therefore, the prescriptions for the solution to the problem lies in bringing about improvement in the students' interactive approach to reading and thereby, improve students' ability to identify the main ideas and details, explicitly stated and implied information, the purpose and the tone of authors in different reading genres: dialogues, articles, essays, directions and poem.

Keywords: Reading Approach, Ability, Strategies, Accuracy, Automaticity, and Reading Speed.

\subsection{Introduction to the Study}

1.1. Background of the Study

Reading is the practice of creating meaning from written texts and requiring the coordination of a number of interrelated sources of information through the dynamic interaction among: "the reader's existing knowledge, the information suggested by the text being read and the context of the reading situation" (Anderson, 2009; NARAP, 2006). Kondo-Brown (2005) defines reading as a means of language acquisition, of communication, and of sharing information and ideas. These definitions underline that reading is a complex interaction between the text and the reader which is shaped by the reader's prior knowledge, experiences, attitude, and language community, which is culturally and socially situated (Grabe, 2009; Pressley, 2006). 
Scholars attempt to underline the difference among reading ability, reading skills, reading strategies and reading approach. For this research context, reading ability is the end result of the reading process when all of the components (loud reading and comprehension as well as reading speed and accuracy) interact successfully (Martinez and Grisalena, 2005). Skills represent linguistic processing abilities that are relatively automatic in their use and their combinations, such as word recognition, syntactic processing etc (Anderson, 2009). Strategies are a set of relatively automatic abilities including previewing, reviewing, predicting, skimming and scanning, guessing from context, inferring, and paraphrasing (Cubukcu, 2008; Dinner 2009; Kondo-Brown, 2006). under conscious control of the reader before, during, and after reading to assist his/her comprehension and understanding of the text being read. Approach to reading is sometimes known as reading model. Approach to reading or reading model the general framework of reading ability, skill and strategy. Approach to reading is three types: bottom-up (lower-level), top-down (higher level) and integrative (eclectic) reading (NashDizel, 2009).

In the framework of students reading approach, there are two very essential concepts needed to be discussed to make the whole idea of this study as clear as possible for the reader. The first concept of reading approach is about textual in textual information. Textual information refers to the directly/explicitly stated message of a text in which the text presents letters, words, sentences, and paragraphs that encode meaning. The second concept relates to the contextual information of a test. This contextual information is the indirectly or implicitly stated that readers need to understand it based on the readers background knowledge and the context of reading situation. In this context, the readers use 'Schemata Theory' by which they bring their background knowledge and experience (content and formal schemata) to determine the meaning of a given text from the writer's 
point of views (Lam, 2009; Siam and Soonandehfar, 2011). According to Martinez and Grisalena (2005) and Strebel (2009),successful readers are expected to understand most of the explicitly and implicitly stated information in a given text within a reasonable time limit. Also the reader should be able to summarize, interpret, and accept or reject printed information (Pressley, 2006).

For the sake of simplicity, these discussions on the approaches, purposes and processes of academic reading are synthesized into three general metaphorical reading models (Grabe, 2009; Pressley, 2006). Many researchers and teachers attempt to create a general understanding of the reading models by means of some reasonable mental framework. General models of reading serve useful purposes, most commonly by providing a metaphorical interpretation of the many processes involved in reading comprehension (Grabe, 2009; Hudson, 2007). Reading approach the process to develop the reader's reading ability. Reading ability is the end result of the reading process when all of the components (loud reading and comprehension as well as reading speed and accuracy) interact successfully (Martinez and Grisalena, 2005). As reading is the interaction of the text and the reader, reading is activated by print, and the meaning is attached to the written texts by the reader (Nash-Dozel, 2010; Lam, 2009 and Strebel, 2009), without which is no reading at all. In this vein, the three general metaphorical reading models were briefly discussed including a few more specific models of reading.

The first metaphorical model of reading is bottom-up model. Metaphorically, bottom- up models (lower-level processes) particularly in L2 discussions suggest that all reading follows a mechanical pattern in which the reader creates a piece-by-piece mental translation of the information in the text, with little interference from the reader's own background knowledge. This lower-level process of reading includes "the word recognition model" of Seidenberg and McClelland (1098). The Word Recognition Model 
of Seidenberg and McClelland (1989) provides a now widely recognised explanation for word recognition processing as it is likely to occur in fluent reading (cited in KondoBrown, 2005). Word recognition models, and there are several, are not seen as models of reading comprehension in themselves, but rather as a depiction of the major input for efficient reading comprehension without accounting for higher-level processing (Buchard $\&$ Swerdzewski, 2009). The key point is that these models are fundamentally bottom-up in orientation, and they account for a considerable amount of what is currently known about word recognition processes under time constraints.

The most fundamental requirement for fluent reading comprehension is rapid and automatic word recognition (lower-level process), which refers to the process of perceiving how written symbols correspond to one's spoken language. In addition, a fluent reader should be able to take in and store language domains together so that basic grammatical information can be extracted (a process known as syntactic parsing) to support clause-level meaning (Grabe, 2009). Syntactic parsing helps to disambiguate the meanings of language domains that have multiple meanings out of context (e.g. words, sentences, essays). Moreover, it helps a reader determine what pronouns and definite articles are referring to in prior text.

Added to this bottom-up or a lower-level process is a top-down model (higher-level processes) that assumes reading as it is primarily directed by reader goals and expectations. In fact, few reading researchers actually support strong top-down views. Top-down model is a set of higher-level comprehension processes that more closely represent what readers typically think of as reading comprehension. Comprehension is the process of making sense of words, sentences and connected text in which top-down 
readers typically make use of background knowledge and experience with text to help them understand written text (Takase, 2007; Pressley, 2006). Beyond understanding and interpreting the ideas represented by the text, they establish purposes for reading, combine reading strategies as needed, make inferences of many types, draw extensively on background knowledge, monitor comprehension, form attitudes about the text and author, adjust goals as appropriate, and critically evaluate the information being read.

The seeming compromise to satisfy everyone is to propose interactive models of reading, again as a general metaphorical explanation. The simple idea behind this view is that one can take useful ideas from a bottom-up perspective and combine them with key ideas from a top-down view. So, word recognition needs to be fast and efficient; and background knowledge serves as a major contributor to text understanding, as it infers and predicts what will come next in the text. Unfortunately, using this logic leads to a selfcontradictory model. As it turns out, the key processing aspects of bottom-up approaches, that is, efficiently coordinated automatic processing in working memory such as automatic word recognition, are incompatible with strong top-down controls on reading comprehension. The automatic processing aspects of comprehension, by definition, need to be able to operate without a lot of interference from the moment-to-moment information gained from background knowledge or massive amounts of inference. These top-down aspects of comprehension must be reserved primarily for higher-level processing.

Under the umbrella of interactive reading approach, a model of reading that was first proposed in the late 1970 s and is still relevant from the point of view of reading researchers is the Interactive Compensatory Model (Rasinski, 2000). This model argues that readers develop efficient reading processes using context clues to understand a text 
better or to decide what a word means (Rasinski, 2000). Another major account of reading model is known as the Simple View of Reading Model (Hoover and Gough, 1990, cited in Dinner, 2009). This model, whose view is compatible with word recognition model and interactive compensatory model, argues that reading comprehension is composed of a combination of word recognition abilities and general comprehension abilities. To confirm this idea, Gough, Hoover and Peterson (1996: 3) present the following analysis.

Skilled reading clearly requires skill in both decoding and comprehension...A reader who cannot decode cannot read; a reader who cannot comprehend cannot read either. Literacy - reading ability - can be found only in the presence of both decoding and comprehension. Both skills are necessary; neither is sufficient (cited in Pressley, 2006).

Dual-Coding Model is also an important specific model of interactive approach to reading (Chard et al., 2009). This model draws on several key concepts from other reading models including the interactive compensatory model, simple view of reading model and verbal efficiency model (Williams, et al. 2011). It also highlights the idea that verbal and visual information represent as learning effectiveness is improved when visual representations for key information match and support prose information from a text. Finally, the Psycholinguistic Guessing Game Model of Reading (Goodman, 1986, 1996, cited in Chard et al., 2009; Pressley, 2006) portrays reading comprehension as a universally applicable iterative process of hypothesising and confirming information based on background knowledge of the readers, expectations about the text, surface features of the text and the deriving of context information from the text (Pressley, 2006; Chard et al., 2009). 
Reading purpose determines the appropriate approach and the level of reading comprehension (Grabe, 2009). Daniel, et al. (2008) claims that reading is an activity with a purpose. Hence, a person reading an academic text and scientific article reads to support or reject an opinion, know the vocabulary used by the author, understand the facts and cause-effect sequences and to recognize ideas that are given and presented as hypotheses in the text. For a reader to be able to read in academic reading, a multi-step process is necessary including at least two activities: word identification and comprehension (Chard, et al., 2009). Moreover, this reading process requires continuous practices, development, and refinement (Phakiti, 2005).

Purposes and approaches of academic reading help the readers to synthesise information from multiple reading sources, or from prose texts and poems. Although such reading is quite different from non-academic readings, it usually involves searching, skimming, or reading for general comprehension (Grabe, 2009). However, in these circumstances, a more critical set of goals must be established for an effective synthesis: the reader needs to remember points of comparison or opposition, assess the relative importance of the information, and construct a framework in which the information will be organised (Torgenson, 2002 and USAID, 2011).

According to Singhal (2001) and Strebel (2009), highly skilled readers use specific integrative approaches to reading in all phases: before, during, and after reading to aid in their comprehension and understanding of the text being read. These reading approaches include various reading strategies, for instance, previewing (reviewing titles, section headings, and photo captions to get a sense of the structure and content of a reading selection); predicting (using knowledge of the subject matter to make predictions about content and vocabulary and check comprehension, using knowledge of the text type and purpose to make predictions about discourse structure, using knowledge about the author 
to make predictions about writing style, vocabulary and content); skimming and scanning (using a quick survey of the text to get the main idea, identify text structure, confirm or question predictions); guessing from context (using prior knowledge of the subject and the ideas in the text as clues to the meanings of unknown words, instead of stopping to look them up) and paraphrasing (stopping at the end of a section to check comprehension by restating the information and ideas in the text) (Cubukcu, 2008; Dinner 2009; KondoBrown, 2006).

In a second language study, Bell (2001); Grabe (2004); Cubukcu, (2008); Dinner (2009) and Grabe (2009) used `data gathering approach to investigate the reading ability of the students and to identify relations between certain types of reading strategies/approaches and successful or unsuccessful second language reading. The successful reader, for example, kept the meaning of the passage in mind while reading in broad phrases, skipped unimportant or less important parts of a text, and had a positive self-concept as a reader. The unsuccessful reader, on the other hand, lost the meaning of the sentences when decoded, read in short phrases, pondered over inconsequential texts, seldom skipped parts of texts as unimportant, and had a negative self-concept (Kitao, Kenji and Miyamoto, 2001).

In this vein, the investigator's attention was attracted by the comments given and discussions made at several teachers' meetings, conferences and other occasions during 2013 to 2017 on the problem of English language teaching quality in Ethiopian Higher Education in general and at Ambo University in particular. During each occasion, English language instructors have commented that the students' inability to read and understand a given text affected not only reading and other language skills, but also other methods of study skills of the students in non-language courses. This is because appropriate strategies in and approaches to reading skills, and thereby, better reading abilities highly contribute 
the successful study skills in non-English texts both in academic and working worlds. However, the instructors of the course have also frequently pointed out that the senior students of the colleges were not as effective readers as the course objectives would expect them to be.

The findings of this research, therefore, can help educators have a better view of their students' approach reading and reading ability. To this objective, the study has suggested some mechanisms and strategies to improve the students' interactive reading ability, which might in turn help the teachers to design suitable reading materials based on the curriculum objectives. Besides, the findings of this study can help policy maker, curriculum designers, course writers and the instructors of the course as well as the researchers in the field to redefine and redirect the policy and the curriculum in a wider scope to solve the problem. As a result, the students' development and progress in their reading ability can be enhanced.

\subsection{Statement of the Problem}

The main concern of the study was the worsening quality of teaching English as a foreign language in all level of education system (Ambachew, 2003; Motuma, 2014; Teshome, 2001). The problem of the quality of education in general has been supposed to makes a vicious circle in education system of the country. For instance, the findings of the previous studies indicate that first-year and senior students of Ethiopian Higher Institutions were unable to understand the explicitly and implicitly stated information in a given text (Ambachew, 2003 and Motuma, 2014). Moreover, primary school teachers in the country were being blamed by the respective stakeholders (for example, students and colleagues) for their poor language teaching (Piper, 2010). The assumption was that the current status of teachers' teaching approach to reading at all level of education system could not support 
their students to learn and develop their fundamental reading ability. As a result, according to an Ethiopian Early Grade Reading Assessment (EGRA, 2010), more than 50\% of the students were unable to answer a single simple reading comprehension questions, and $30 \%$ of the students were illiterate in the country, after attending school for three or four years (Piper, 2010).

Moreover, an exit test report made by Ministry of Education (MOE, 2017) indicates that the achievement of the English major students of Ambo University is decreasing from year to year. For example, the average score of the third year ELT students, who graduated in June 2017, was below that of their counterparts, who had graduated in 2016 in both the instructors' Assessments (IA) of the University and exit test. The result of exit test shows that about $11(21.15 \%)$ of students scored less than $50 \%$ in 2015, whereas $15(28.85 \%)$ of the students scored less than 50\% in 2016 in the test. Moreover, the very least point of the University EFL students' result is 23 points out of 100 in the test in 2017. The result also indicates that the students, who graduated in 2017, scored an average of 66 out of 100 points in a reading test, two points less than in 2015 and four points below the 2016, an average of 70 .

However, being in this serious and urgent problem, no research has been conducted to investigate the students' approach to reading, and very few studies were conducted to determine the students reading ability at graduating level in the higher education (Motuma, 2014). For this reasons, the need for the investigation of reading ability of the University students is clear. The main objective of this study was to investigate the reading approach and ability of English major third year regular student of Ambo whether they were able to recognize the main ideas and details, the directly stated and implied information, purpose and the tone of a given text. 


\section{Basic Research Questions}

The research attempted to answer the following basic questions:

1. To what extent do the students use reading strategies to understand a given text?

2. What types of reading strategies do the students use to recognize the textual information presented in a given text?

3. What types of reading strategies do the students use to understand the contextual information implied in a given text?

4. Is there any difference between the successful and unsuccessful readers in their approaches to reading?

Research Design and Methodology of the Study

The Study Unit

As one of the 44 government in Ethiopia, Ambo University has totally nine, five Colleges, three Institutions and a School. Among the colleges are Social Science and Humanity, which are organized into eight streams from which department of English Language and Literature is one. English Language and Literature is taught undergraduate, masters and PhD programs. During the study time, there were 52 (31 male and 21 female) English major third-year regular students who were learning for their first degree program.

The Research design of the Study

This study was grounded on pragmatism as a research paradigm aligned with a mixed research design (Cresswell, 2014; Shannon-Baker, 2016). In approaches to reading ontology, the research questions in the study were trying to address the problem of reading inability in reading course (Shannon-Baker, 2016). Epistemologically, this study required the use of both quantitative and qualitative approaches to address the research problem (Cresswell, 2014; Shannon-Baker 2016). As a result, descriptive survey design was 
employed to achieve the purpose of this study.

The Participants and Sampling Techniques

Purposive sampling technique was employed since the target population for the study is known and small to manage. The sampled population was stratified into successful and unsuccessful groups. In addition, to make the interview manageable and the sample as representative as possible for the population, eight students (equal number of highly successful and unsuccessful groups) were purposely determined from the reading comprehension test performance for the loud reading tests and for the retrospective interview.

Data Gathering Instruments

A "Triangulated Data gathering" approach was used in this study to adequately assess the data and determine the reading ability of the students from various perspectives: test, questionnaire, interview and observation (Perlez and Linday, 2003; Sharon, 2006; Daniel, et al., 2008; Williams, et al., 2011). Hence, this study employed three main data gathering instruments: a reading achievement test, approaches to reading questionnaire and structural retrospective interview for their good concurrent validity.

\section{Reading Achievement Test}

To investigate the students' English reading ability, two consecutive tests were conducted at different times (one month interval) following Sharon (2006) procedure to minimize the test fatigues and estimate the reliability and validity of the test using the correlation between the scores of the two tests. Moreover, in order to enhance the reliability of the tests and to ensure one correct response to each question, Williams, et al. 
(2011) and Daniel, et al (2008) methods were adopted. Three English language instructors were invited in the construction and administration processes of the tests. The first test was given on 16/10/2017 and the second test was administered on 20/11/ 2017 with a completion time of 2:30 hours each test. On the day of the each test, the respective questionnaire was administered in their classroom to all the students in the afternoon to know what approaches and strategies and how they understood the textual and contextual items during the reading comprehension tests.

Each reading test had five sections/genres: dialogues, directions, article, essays, and poems because the genres help the researcher to align the test questions with the course objectives of the diploma program. Based on Sharon (2006), 10 multiple choice questions were asked from each of the five genres with each question carrying a point value of 2 (i.e. $5 \times 10 \times 2=100$ ). To make the passages reasonably challenging for the college students and fit them to the students' background and the objectives of the reading courses, all the reading passages contained three to five new words and familiar contents for most of the University students in Ethiopian context. In other words, the reading passages did not require the students' special technical skills to understand them. The difficulty level and the discriminating power of the tests were similar, ranging respectively from $41 \%-60 \%$ and 0.30

- 0.50, which means that the questions were ranged between average and good items as of the standard. All the test questions set were thematically sorted into one of the variables of approaches to reading (Hudson, 2007): the ability to understand the contextual information in the texts including the main ideas, inferences/implication, purpose and the tone of writing and the ability to understand the textual information that entails specific fact or details, references in all the genres.

Chard et al. (2009) and USAID-AED/IQPEP (2010) parameters and interpretation 
guidelines were adapted and used to interpret the results of the students. This includes: $85 \%-100 \%$ points $=$ successful $/$ interactive reader $; 70-84 \%$ points $=$ successful $/$ top-down reader; $50-70 \%$ points $=$ unsuccessful/bottom-up reader and below $50 \%$ points $=$ unsuccessful / frustrated reader.

Approaches and Reading Questionnaire

The researcher adapted a three-page questionnaire with 48 open-ended and 5 close- ended items from Sharon (2006) and Williams, et al., (2011) to determine the students'approaches to reading and strategies to answer the test items. These approaches to reading include various reading strategies, for example, previewing (reviewing titles, section headings, and photo captions to get a sense of the structure and content of a reading selection); predicting (using knowledge of the subject matter to make predictions about content and vocabulary and check comprehension, using knowledge of the text type and purpose to make predictions about discourse structure, using knowledge about the author to make predictions about writing style, vocabulary and content); skimming and scanning (using a quick survey of the text to get the main idea, identify text structure, confirm or question predictions); guessing from context (using prior knowledge of the subject and the ideas in the text as clues to the meanings of unknown words, instead of stopping to look them up).

Moreover, the questionnaire include various reading strategies such as paraphrasing (infer and refer interpreting and summarizing as well as restating the information and ideas in the text at the end of a section to check comprehension) (Cubukcu, 2008; Dinner 2009; Kondo-Brown, 2006) to understand a given text and to cross-check the students' confidence with their achievements in the tests. The first parts of the questionnaire included a 5-point Likert scale: 1 (Never), 2 (sometimes), 3 (often), 4 (usually) and 5 (always). In the second part of the questionnaire, each student was asked to rate whether he/she had done the tests with 'quite easily=3', 'with some difficulty $=2$ ' or 
'with great difficulty $=1$ '. The questionnaire was pre-tested (using the polite testing process) and all ambiguous statements were detected and improved on the final questionnaire administered. Finally, in the afternoon, on the day of the last test, the questionnaire was administered to all the students in their classroom to know what approaches and strategies they developed and employed to understand the textual and contextual items of the reading comprehension tests.

\section{Semi-Structured Retrospective Interview}

A semi-structured retrospective interview was used to supplement the test and the questionnaire. The interview helped the researcher to further explain the nature and type of students' approaches to reading and reading strategies to answer the reading comprehension test and the extent to which the individual test takers differed from one another in this respect. The retrospective interview was conducted with eight test takers. The semi-structured retrospective interview conducted consecutively after the administration of the questionnaire and the comprehension test to eight selected students (four each from successful and unsuccessful group). This help the researcher to further asses the students' approaches to reading and reading strategies they had adopted while answering the reading test items.

All the eight students selected for the retrospective interview were coded as $\mathrm{A}-\mathrm{H}$ to keep their results confidential. The first four of them (A-D) were the top achievers, and the other four $((\mathrm{E}-\mathrm{H})$ were from the lower achiever in the comprehension tests. The interview was conducted in face-to-face individually with each student. Audio taperecorder was used to record their voices in order to analyze their interview responses latter on in the context of the study. The maximum time taken by each student to complete the interview was an hour, totally eight hours. 
Methods of Data Analysis

The descriptive statistics such as percentages, mode, median, range, mean were employed to quantitatively describe and explain the students' approaches to reading and reading strategies as well as their ability. Moreover, the data obtained through interview and open-ended questions of the questionnaire were qualitatively analysed, and the findings were used for triangulating the quantitative data.

The Results and Discussion

\section{Reading Comprehension Test}

The results of the students' reading comprehension tests are presented in Figure 1. The number of students was converted into percentage for clarity. The result reveals that only $5(9.62 \%)$ and $6(11.54 \%)$ of students scored $75-80 \%$ and $70-75 \%$ points respectively. Similarly, equal number of students, 7(13.46\%) of them have scored $65-70 \%$ and $60-65 \%$ points respectively. However, 23(44.23\%) of the students have scored below $50 \%$ in the test as summarized in Figure 1 below.

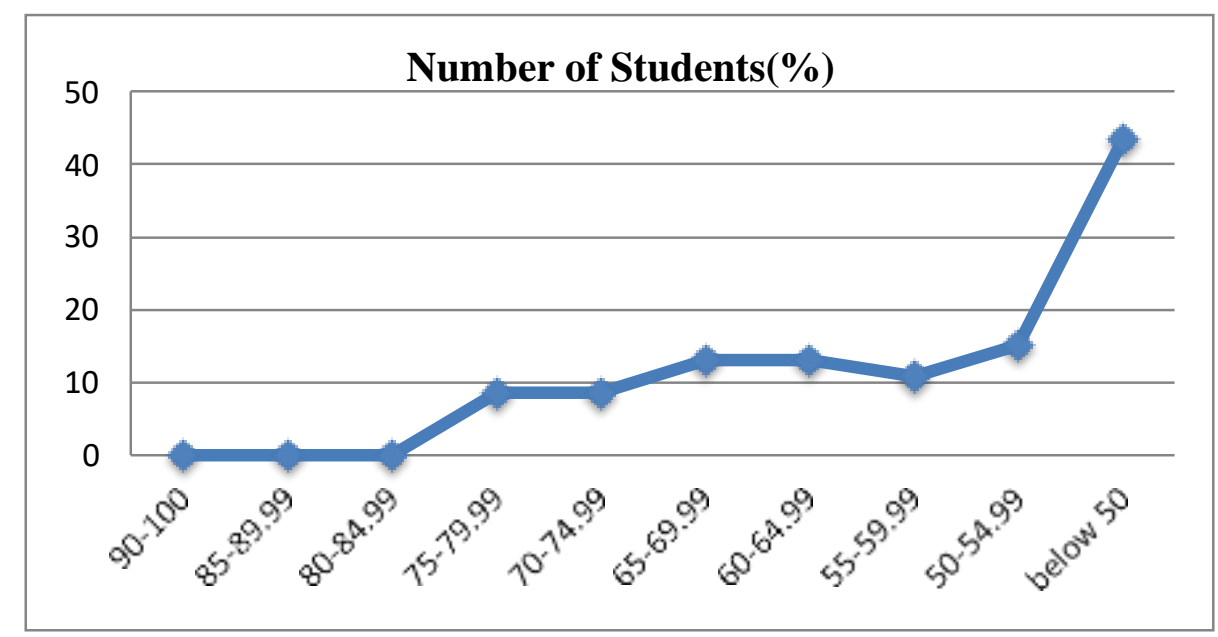

Figure 1: Reading Comprehension Test Results by Percentage

Figure 1 also shows that no student has scored greater than $80 \%$ in the test. These 
results show that most of the students were unsuccessful readers because their approach to reading or they were bottom-up or lower-level readers. In other words, the results of this study in which almost half, 23(44.23) of the students scored below 50\% reveals that they could not understand a given text in general and most of the contextual information in the text in particular as the teaching module objectives had expected. However, 11(21. 15\%) of the students were judged to be successful readers or top-down reader or higher-level reader, $18(34.62 \%)$ of them were successful readers, but their approach to reading was bottom-up, or they were lower-level readers; whereas students was found to be very interactive readers.

Therefore, 41 (78.85\% of the English major third year regular students of the University are classified as "bottom-up readers" based on the criteria as developed by Chard et al (2009) and USAID-AED/IQPEP (2010). This is in agreement with the findings of Martinez and Grisalena, (2005) and Chard et al. (2009) who both had reported that most of their students are frustrated and very few of them are good readers.

Figure 2 also shows the percentage of students who scored above and below $50 \%$ to compare the students' performance using the five reading genres. Most, 42 (80.77\%), of the students have scored above 50\% in essay questions, however, most, 38 (73.08\%) have scored below $50 \%$ in poems. Items in dialogues were the next easier as $40(76.91 \%)$ of the students scored above 50\%. In contrast, newspaper article questions were difficult for the students with only $23(44.23 \%)$ scored above $50 \%$ in the test. However, directions seem to present the average level of difficulty in students' test results, as of only $29(55.77 \%)$ of the students scored above $50 \%$ of the test as indicated in the following figure. 


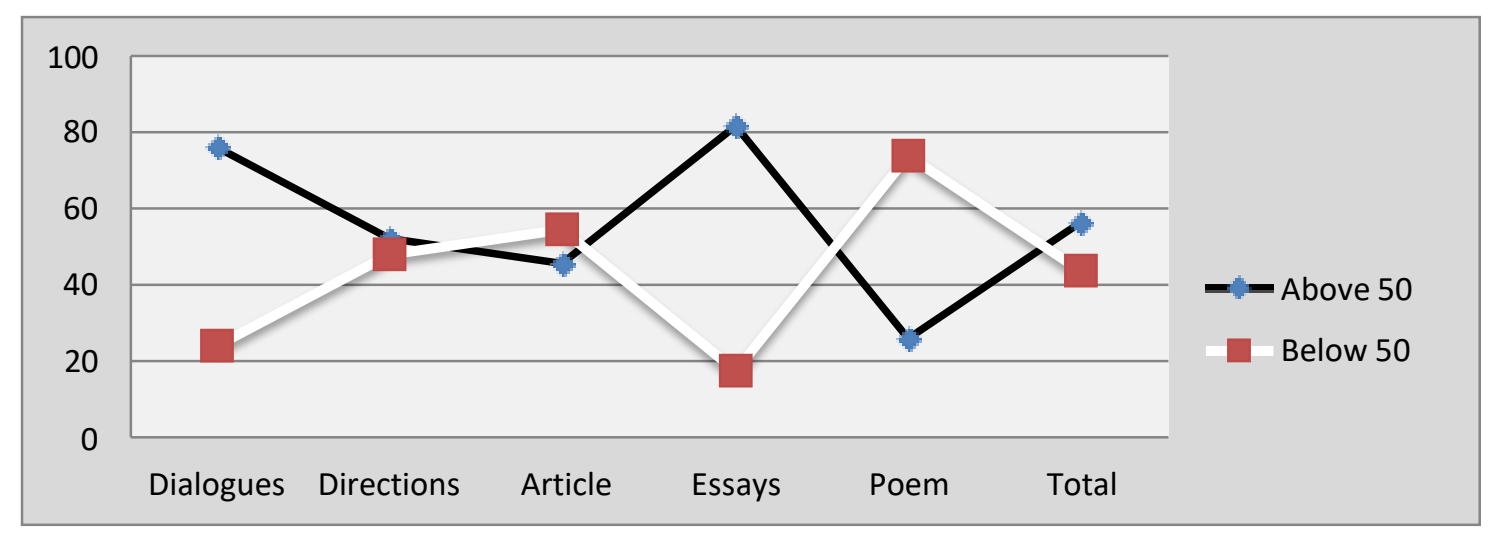

Figure 2: Reading Comprehension Test Results by Genres

Figure 2 reveals that though equal time was allotted to each genre, the students' results were highly varied. The results indicated that students were able to read and answer questions in the essay better than dialogue, direction and newspaper article in such order and the least in poem. The reading comprehension test result variation by genre is presented in.

Table 1. The results indicated that reading ability of the students varied a great deal according to genres. For example, the students' total mean scores were higher for essays $(17.5 / 20)$ and dialogue $(15.8 / 20)$ when compared to others in the test. However, poem recorded the lowest value $(9.4 / 20)$ in the tests.

Table 1: Reading Comprehension Test performance by genre

\begin{tabular}{|c|c|c|c|c|c|c|c|c|}
\hline \multirow{2}{*}{$\begin{array}{l}\text { Sections/ } \\
\text { Genres }\end{array}$} & \multicolumn{2}{|c|}{ First Test } & \multicolumn{2}{|c|}{ Second Test } & \multicolumn{2}{|c|}{ Total } & \multirow{2}{*}{$\begin{array}{l}\text { T- } \\
\text { Test }\end{array}$} & \multirow{2}{*}{$\begin{array}{l}\mathrm{P}- \\
\text { value }\end{array}$} \\
\hline & 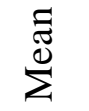 & $\hat{\Omega}$ & 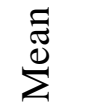 & $\hat{n}$ & 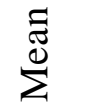 & $\hat{n}$ & & \\
\hline Dialogue & 8.0 & 3.6 & 7.8 .0 & 3.4 & 15.8 & 3.5 & 0.06 & 1.21 \\
\hline Direction & 6.1 & 4.1 & 6.3 & 3.2 & 12.4 & 3.0 & 0.05 & 1.23 \\
\hline Articles & 4.9 & 4.4 & 4.7 & 3.1 & 9.6 & 2.1 & 0.56 & 1.12 \\
\hline Essay & 8.7 & 3.3 & 8.8 & 3.8 & 17.5 & 2.9 & 0.03 & 1.02 \\
\hline Poem & 4.6 & 2.8 & 4.8 & 2.7 & 9.4 & 3.1 & 0.07 & 1.08 \\
\hline Total & 32.3 & 3.7 & 32.4 & 2.98 & 64.7 & 2.8 & 0.05 & 1.01 \\
\hline
\end{tabular}

Table 1 presents the comparison of the first and the second tests mean, standard deviation and t-test to determine the reliability of the tests in general. The distributions of the results of first test and second test are very similar because the t-test. $t=0.05$ at $p=$ 
1.01 between the mean scores of the first and the second tests were almost the same. Referring to Table 1, the mean values of each genre also confirms the same phenomena that there was no difference between the first and the second tests. The result of the analysis showed that the students scored on average $64.7 \%$ in the test, and the highest score of the students was $78.9 \%$ and $31 \%$ being the least point scored (see table 1 ).

The results also shows that the difference between the overall mean score of the first test (32.2) and that of the second (32.4) is 0.2 , which signifies that the two tests are consistent and reliable to describe the students' reading ability. The result of this study is consistent with the claims by Grabe (2004); Flowers (2007) and Williams et al. (2011) all of which had reported that the results of students in the tests are correlated and consistent to explain the problems of the students in their respective studies. This means, the distributions of the results of the tests that are given at different time interval must be similar to generalize the variation of the students reading ability on the bases of the reading genres. Therefore, the results of this study shows that the students are skillful in reading some particular genres but not in others for some reasons which might be related to teaching qualities and/or components of the teaching modules.

The further analysis of the reading comprehension test result focused on the students' ability to understand the textual and contextual information in a given reading passage. The analysis into five themes based on the purposes of the questions: 1) the main ideas, 2) details/specific facts, 3) reference/directly stated information, 4) inference/implied information and 5) purpose and the tone of the author in a given text as stated in Figure 3. 


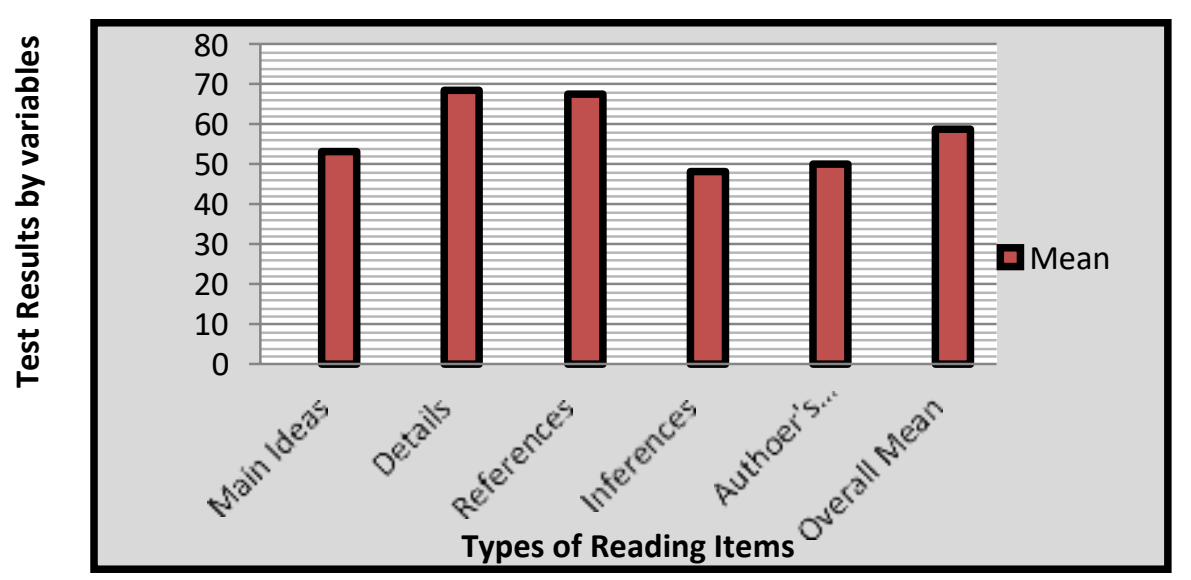

Figure 3: The Reading Comprehension Test Results by Reading Variable

Figure 3 also shows that the percentage of mean $69.3 \%$ shows that the students scored a higher was result in the questions that require students to identify detailed questions followed by reference questions with $68.3 \%$ and answers $50 \%$ of the author's purpose right in the test. However, inference and main idea questions recorded $46.9 \%$ and $52.3 \%$ respectively. This indicated that students were bottom-up readers or lower-level reader because they were unable to guess the meaning of new words based on clues and contexts and unable to use their background knowledge and generalize the contents of a given reading text. In other words, they focused exclusively on the textual or word recognition approach to reading as opposed to the contextual ability.

These findings are closely consistent with that of Pressley (2006); Takase (2007); Anderson (2009) and Grabe (2009) in which they have claimed that students in their respective studies were using more lower-level reading (bottom-up) strategies than the higher level (top-down) strategies. Most $89.7 \%$ of the students participated in this study were not using higher level reading strategies including previewing, predicting skimming and scanning guessing new words and paraphrasing information recommended by Cubukcu (2008); Dinner (2009) and Kondo-Brown (2006) to aid their comprehension and understanding of the text being read. The findings of this study also showed that students were not able to understand higher-level or contextual information that more closely 
represent what readers typically think of as reading comprehension (Singhal, 2001; Strebel, 2009).

To wind up, the overall findings of the tests implied that the reading process and ability of the students is best expressed by the lower- level reading or bottom up reading approach, which focuses on a mechanical pattern in which the readers create a piece-bypiece mental translation of the information or textual information in the text, with little interference from the students' own background knowledge or contextual information. This is because the students answered relatively more specific facts, details and reference questions than general/main ideas, implied, author's purpose and tone of the writing questions in the tests. The following section presents the approach and strategy questionnaire in which the students rated themselves to underline their approaches against a three levels scale.

The Result of the Students' Questionnaire Analysis

Table 2 shows the mean of the students' self-rating on a 3-point reading ability rating scale.

Table 2: Students Self-rating on Reading Ability Scale

\begin{tabular}{|l|l|l|}
\hline No & Statements (N=52) & $\sum^{\text {J }}$ \\
\hline 1 & I put my best effort to perform every question in the text. & 2.83 \\
\hline 2 & $\begin{array}{l}\text { I read and understand the words in the texts and in the questions } \\
\text { easily }\end{array}$ & 1.5 \\
\hline 3 & I got the meaning of the unknown word from the context & 1.6 \\
\hline 4 & I understood specific facts in the text easily & 2.53 \\
\hline 5 & I understood the implied information in the text easily & 1.2 \\
\hline 6 & I recognized the purpose of the writer of the text easily. & 1.30 \\
\hline 7 & $\begin{array}{l}\text { I used my background knowledge about the topics and the } \\
\text { language items in the texts }\end{array}$ & 1.5 \\
\hline & I used the topics understand the language items in the texts & 1.9 \\
\hline Weighted Mean & 1.75 \\
\hline
\end{tabular}


The weighted mean of the students' self-rating was 1.75 , which means the majority of students read and answered the test questions with "some difficulty." However, the great majority of students reported that they "had great difficulty" to understand new words (1.6), to elicit the implied information (1.2), and to use their background knowledge (1.5) and topics (1.9) in the texts. However, they were able to answer the specific facts quite easily (2.83) and the directly stated information in the texts using scanning techniques than other questions. The next table illustrates the strategies used by the reader to understand each item in the test.

Table 2: Students' Responses on Matrices of Strategies to Understand the Items in the Test

\begin{tabular}{|l|l|l|l|l|l|l|l|}
\hline Strategies & $\begin{array}{l}\text { Main } \\
\text { ideal }\end{array}$ & $\begin{array}{l}\text { Deta } \\
\text { ils }\end{array}$ & $\begin{array}{l}\text { Refer } \\
\text { ences }\end{array}$ & $\begin{array}{l}\text { Infere } \\
\text { nces }\end{array}$ & $\begin{array}{l}\text { Authors' } \\
\text { Purpose }\end{array}$ & $\begin{array}{l}\text { Weighted } \\
\text { Mean }\end{array}$ & Rank \\
\hline Guessing & 1.1 & 2.1 & 2.1 & 1.1 & 1.1 & 1.5 & 5 \\
\hline Previewing & 1.2 & 1.4 & 1.6 & 1.2 & 1.4 & 1.36 & 6 \\
\hline Predicting & 1.01 & 1.3 & 1.5 & 1.4 & 1.2 & 1.28 & 7 \\
\hline Skimming & 2.5 & 2.6 & 2.8 & 2.1 & 2.5 & 2.5 & 3 \\
\hline Scanning & 2.7 & 2.8 & 2.9 & 2.4 & 2.6 & 2.68 & 2 \\
\hline Referring & 2.8 & 2,9 & 2.7 & 2.6 & 2.8 & 2.73 & 1 \\
\hline Inferring & 1.3 & 1.7 & 1.6 & 1.7 & 1.8 & 1.62 & 4 \\
\hline Average Mean & 1.80 & 1.98 & 2.17 & 1.79 & 1.91 & 1.95 & \\
\hline
\end{tabular}

Table 2 above reveals the matrices in which various strategies used by the students to understand the various items of in the tests. The table indicated that the students most of them use referring (2.73), scanning (2.68) and skimming (2.5) strategies in descending to understand more of the references (2.17), detailed (1.98) and authors' purpose items in the tests. On the other hand, the strategies used least frequently by the students were predicting (1.28), previewing (1.36), guessing (1.5) and inferring (1.62). As indicated in Table 2, the average mean of the frequency of reading strategies used by the students in general was 1.95 . 
This shows that only $65 \%$ of the students used the strategies only "sometimes" while they were answering the test questions. Specifically, $60 \%$ of the students reading strategies understand the main idea (1.80) that was below the average mean of the computed data. Relatively lower than the main ideas, about $59.7 \% \%$ of the students also used strategies to identify the inferences/ implied information in the reading tests. However, more than $73 \%$ and $66 \%$ of the students used reading strategies to identify the reference and directly stated information items in the test respectively. Therefore, it was not easy for the students to elicit the main ideas, the implied information, the purpose and the tone of authors in the texts.

The results in Figure 5 indicate that most of the students used frequently the strategies that help them to understand the reference and specific facts in the texts. To compare the frequency of the strategies used by the students with their results in the tests as in Figure 5, the mean of the reading strategies has been converted to its percentage. Hence, the students' ability to identify the main ideas (60\%) implied information $(59.7 \%)$ and author's purpose $(63.7 \%)$ was less than their ability to identify details $(66 \%)$ and references $(73.3 \%)$ in the texts. As it has already stated figure 3, the result of the students in the test were reported that they $(52.3 \%)$ the main ideas; implied information $(46.9 \%)$ and author's purpose (50\%) was less than to identify details (69.3\%) and references (68.3\%). The average point in the tests was $64.7 \%$. Hence Figure 4 compares the result of the students in the test with the strategies they used to answer the items in the test.

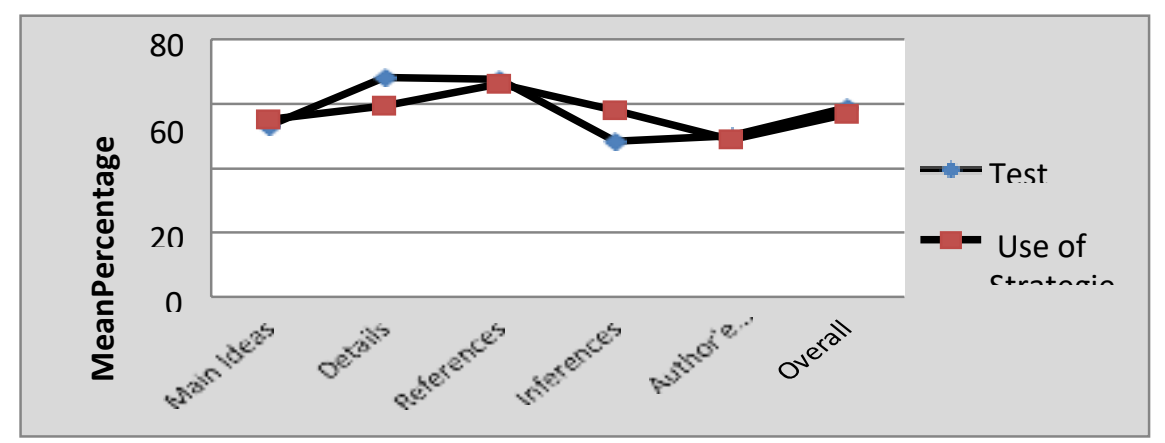

Figure 4: the Relationship between the test Results and use of strategies

Figure 4 shows that the there is a close relationship or consistency between the 
students' results in the test and the strategies they used to answer the questions in the test. This can be interpreted as the type of the strategies they use necessarily determines their ability to answer certain types of items in the tests. This result showed that the students of the University were unable to comprehend the items related implicitly stated, main idea, purpose and tone of the authors in the text because they seek for piece of information including explicitly stated, detailed and reference items in the text. This also implies that as they concentrated more on specific facts, they failed to find the main ideas from the whole content and thereby, unable to make inferences to develop ideas or images based on what is implied in the text but not stated. Normally, the findings of this study are closely consistent with the findings obtained in Soonandehfar (2011); Anderson (2009); NashDizel (2009) and Lam (2009) that the result of the test depends on the strategies the students use to understand a given text and answer the test questions. As a result, these scholars have similarly reported a positive relationship between the results of the reading ability test and the strategies readers use.

The findings of this study also revealed that they were not able to generalize the information in the tests and to determine the relationship between single events and the larger situation or other events. Moreover, they failed to evaluate and identify the tone/mood of the text: the author's feeling which he/she wanted to convey across to the reader. In other words, they were unable to see the "big picture" or abstract idea and characterization in a given text. Thus, this result of this study indicated that the students reading approaches and strategies primarily focused on the recognition of specific language aspects of the texts with little interferences from their own background knowledge. The key point here was that the students were fundamentally bottom-up orientated because they considerably depended on the textual information of the texts.

3.2. The Result of Retrospective Interview Analysis 
The semi-structured retrospective interview was used to supplement the result of the test and the questionnaire. The interview helped the researcher to make some concepts in relation to the textual and contextual information of the texts and further explain the nature and type of students' approaches to reading and reading strategies to answer the explicitly and implicitly stated information in reading comprehension test and the extent to which the individual test takers differed from one another in this respect. The interview was conducted with four successful and other unsuccessful test takers. The successful ones or the top achievers in the test were coded as A-D and the other unsuccessful or the lower achiever students in the comprehension tests were coded $\mathrm{E}-\mathrm{H}$ to keep their results confidential.

The results of face-to-face interview disclosed that the students of the university had adopted bottom-up approach to reading or lower-level reading strategies to understand a given text and thereby, answer more textual the reading comprehension test items. This means that as it is clearly identified in the analysis of the test and questionnaire, almost all the interviewee were confirmed that they can easily recognize the recognize words, phrases, sentence level and explicated stated textual information in all the five text. On the other hand, they could not construct the implied meaning from the recognized words. That means, they could not read between and/or beyond the line to search for contextual and implied information in all the five genres. However, they think they were better to understand essays and dialogue than others such as articles, directions and poem from which poem is exceptionally difficult for them. Student A scored the highest 78 point in the test. The student scored more than 15 points out of 20 items in all the five genres. The minimum point the student was $15 / 20$ in poem and the maximum was $19 / 20$ point in easy. Analyzing the result of the student, one can realize that there might be difference in either 
in proper use of relevant reading strategies or the level of difficulty among the reading texts or the items.

The student, with the other three successful readers, claimed that they read a given text fluently and answer most of the reading comprehension test questions correctly. However, the students were unable to score better than $78 \%$ in the test that shows that though they were successful readers, students A and B were top-down or higher level readers, students $\mathrm{C}$ and $\mathrm{D}$ were bottom-up readers; there were no interactive reader among them. However, there was sensible difference between the successful and unsuccessful readers. The results of the retrospective interview show that the successful students (A-D) used more reading strategies more frequently than the unsuccessful students $(\mathrm{E}-\mathrm{H})$. Unlike the unsuccessful readers, successful students were able to answer questions that require them to employ context clues, attempt to relate important points in text to the whole, use prior knowledge to interpret text, attempt to infer information from the text and so forth. The present study shows similar results with the findings identified by several scholars (Bell (2001); Grabe (2004); Cubukcu, (2008); Dinner (2009) and Grabe (2009) and Wiggins (2005); Wang (2009) and Sharon (2006) by which they have identified the relationships between the types of reading strategies the successful or unsuccessful students used and their readers ability in their respective studies. Lam (2009); Cubukcu (2008); Kitao, Kenji and Miyamoto (2001) also claim the same finding that the unsuccessful reader lost the meaning of the sentences when decoded, read in short phrases, pondered over inconsequential words, seldom skipped words as unimportant, and had a negative self-concept.

4. Conclusions and Recommendations

\subsection{Conclusions}

As reading is the ability to draw meaning from the printed page and interpret this 
information appropriately, whatever the genre is, the University English major senior students could not read and understand a given text at the level. Evidently, almost all (89.7\%) of the students of ACTE students were exclusively limited to bottom-up approaches to reading and frustrated to determine the main ideas and implied information in the texts. In other words, no student answered more than $78 \%$ in reading comprehension items correctly in the tests. Moreover, half of the students could not answer above $50 \%$ in the comprehension questions.

The reading ability of the students varied a great deal according to the reading genres and variables. The students could read and understand essays and dialogues better than poems and articles. Similarly, most of the students were able to identify the detailed or specific facts than the main ideas, implied information, purpose of the author and the tone of a given text because they entirely focus on a mechanical pattern to create a pieceby-piece mental translation of the information in the text. Therefore, the reading ability of the students was best expressed by the lower- level reading or bottom up reading approach.

The results of the study show positive relationships between the comprehension test results of the students and the types and the frequency of reading strategies they use to understand a given text. In other words, the results claimed that the successful readers use various strategies more frequently than unsuccessful students, and correspondingly, the results of the reading comprehension test of the students were lower in the main ideas, the implied information and the author's purpose and the tone of the text than in others.

\subsection{Recommendations}

Training the students to properly use the proper reading approaches and strategies so as to improving reading ability and enhancing reading skills of English Major College students must remain a top priority for the stakeholders. Therefore, Ministry of education 
Ambo University, Department of English Language and literature and the teachers in the field should work together for the improvement of the reading curriculum of the Universities in general. Specifically, English language teacher-educators and students in the field should play their roles to improve the components, authenticity and appropriateness of the teaching materials being used to incorporate poems and articles. In addition to this, they need to set appropriate assessment tools and thereby use them to plan and properly implement the remedial classes for the students at risk of reading failure to improve their reading ability in the University in general.

The English language instructors should give emphases to the reading strategies and skills that help the students identify the main ideas, implied information and author's purpose and the tone of the text than others. Moreover, they should effectively work to link the appropriate reading assessment tools and methods to the reading instruction or remediation as to the objectives of the course specifies. Besides, they must provide students with opportunities to practice the collaborative learning strategies they have been taught through direct strategy-instruction and modelling. Students must also determine their strengths and weaknesses in terms of strategy use to improve their reading ability. They ought to practice to understand the meaning of a given text. In short, the students must use all the opportunities to practice the reading strategies they have learnt. They should also work to develop the culture of collaborative learning strategies to improve their overall reading competence.. In general, the prescriptions for the solution to the problem lies in bringing about improvement in the students' interactive approach to reading and thereby, improve students' ability to identify the main ideas and details, explicitly stated and implied information, the purpose and the tone of authors in different reading genres: dialogues, articles, essays, directions and poem. 


\section{Bibliography}

Afflerbach J., pearson T. \& paris F.,(2008) Research on reading. Modern Language Journal, 75(4), 460-472.

Ambachew M. D. (2003).A Review of the Ethiopian Related Literature on Reading Ability.University of Pretoria ltd, (pp.312-4610

Anderson, N. J. (1991). Individual Differences in Strategy Use in Second Language Reading and Testing, Modern Language Journal, 75(4), 460-472. (2009) An Investigation of Reading Abilities in Advance level French Students. Modern Language Journal, 75(4), 460-472.

Alemu Hailu, (2009). Ill-designed Reading Activities: The Case of a Unit in Grade 11 English Textbook, The Ethiopian Journal of Education, Vol. XXIX (2): (34-59), Bell, Timothy, (2001). Extensive Reading: Speed and Comprehension. The Reading Matrix; Vol. 1, No. 1, April 2001, E-mail: timothy@hsc.kuniv.edu.kw

Chard, D.J., Ketterlin-Geller, L.R., Baker, S.K., Doabler, C., \& Apichatabutra, C. (2009). Repeated reading interventions for students with learning disabilities: Status of the evidence. Exceptional Children 75(3), 263-281.

Cubukcu, F. (2008). How to Enhance Reading Comprehension through Metacognitive Strategies, The Journal of International Social Research, 1(2), 83-93.

Daniel J. Acheson, Justine B. Wells, and Maryellen C. MacDonald, (2008). New and Updated Tests of Print Exposure and Reading Abilities in College Students, University of Wisconsin, Madison, Wisconsin, (Pp.278-289)

Desrochers, A., \& Glickman, V. (2009). Criteria for the Evaluation of Reading Assessment Tools, Encyclopaedia of Language and Literacy Development (pp. 19). London, In: Canadian Language and Literacy Research Network. Retrieved on 01/08/2011 from http://literacyencyclopedia.ca/pdfs/topic.php?topId=280 
Dinner, L. R. (2009). “Analysis of the Metacognitive and Affective Components of Learning on Reading: Achievement of Striving Readers with and without a Reading Disability", (PhD Thesis), University of Kansas.

Flowers, A. Lamont, (2007). Recommendations for Research to Improve Reading Achievement for African American Students. Clemson University: South Carolina, USA. (pp. 165-178)

Grabe, W. (2004). Research on Teaching Reading. Annual Review of Applied Linguistics, $24,44-699$.

Grabe, W. (2009). Research on Teaching Reading. Annual Review of Applied Linguistics, 24, 44-699

Hudson, T. (2007). Teaching Second Language Reading. Oxford, England: Oxford University Press.

Kitao, K. \& Miyamoto, H. (2001). Japanese College Students' English Reading Ability: A Study Based on Testing, ERIC Document Reproduction Service No. ED 381766.

Kondo-Brown, K. (2009). Heritage Background, Motivation, and Reading Ability of Upper- level Postsecondary Students of Chinese, Japanese, and Korean, Journal of Reading in a Foreign Language, Volume 21( 2): 179-197

Kondo-Brown, K (2006). Affective Factors and Japanese L2 Reading Ability. Reading in Foreign Language Journal, (18): 55-70. (2005). Differences in Language Skills: Heritage Language Learner Subgroups and Foreign Language Learners. The Modern Language Journal, 89, 563-581.

Lam, W. (2009). Examining the Effects of Metacognitive Strategy Instruction on ESL Group Discussions: A Synthesis of Approaches. Language Teaching Research, 13 (2), 129-150.

Martinez, P. and Grisalena, Jesus (2005) Reading Ability at 15 Years of Age - PISA Scales. 
ISEI-IVEI: Australia.(13): 172-203.

Nash-Ditzel, S. (2010). Metacognitive Reading Strategies Can Improve Self-Regulation. Journal of College Reading and Learning, 40(2), 45.

National Accessible Reading Assessment Projects (NARAP) (2006). Defining Reading Proficiency for Accessible Large scale Assessments: Some Guiding Principles and Issues, Minneapolis, MN: Author.

Perlez, A. and Lindsay, T., (2003). Methodological Triangulation in research families: Making Sense of Dissonant, International Journey of Social Research Methodology, 6, 25-40.

Phakiti, Aek (2005). A Close Look at the Relationship of Cognitive and Meta-cognitive use to EFL reading Achievement Test performance.

Piper, Benjamin, (2010). Ethiopian Early Grade Reading Assessment, Data Analysis Report: Language and Learning. Ed Data II, Task order 7\&9, USAID/Ethiopia.

Pressley, M., Gaskins, I., \& Fingeret, L. (2006). Instruction and development of reading fluency in struggling readers. In S.J. Samuels \& A.E. Farstrup (Eds.), What research has to say about fluency instruction (pp.47-69). Newark, DE: International Reading Association.

Sharon, Switzer (2006). A Triangulated Data Approach to Assessing Academic Reading English of English Language Learners, East Stroudsburg University: Pan African Association of Linguistics.

Siam, Elmira N., and Soozandehfar, Seyyed M., (2011) Metacognitive Awareness of Reading Strategies and Reading Comprehension, California Linguistic Notes, Volume XXXVI No. 1Shiraz Universit, Iran

Singhal, Meena, (2001) Reading Proficiency, Reading Strategies, Metacognitive Awareness and L2 Readers. The Reading Matrix, Vol. 1, No. 1. 
Strebel, C. S. (2009). "An Investigation of Linguistic, Cognitive, and Affective Factors that Impact. English Language Learners' Performance on a State Standardized Reading Achievement Test" (Doctor of Philosophy Dissertation), University of Central Florida.

Takase, A. (2007). Japanese High School Students' Motivation for Extensive L2 Reading. Reading in a Foreign Language, 19, 1-18.

Teshome Demisse, (2001).Assessment of Pupils' Achievements in the Teaching of English:Training and Practice in Focus, The Ethiopian Journal of Education, Vol. XXI (1): (34-79).

Torgenson, J.K. (2002). The prevention of reading difficulties. Journal of School Psychology, 40, 7-26. Vacca, J and Vacca, L (1989) Content Area Reading, Third Edition, Scott: London.

United States Agency for International Development/Improving Quality Education Program (2010). Continuous Assessment and How to Use it: Teachers Module 3.AED: A. A. Ethiopia, (pp.20-43).

United States Agency for International Development , (2011). Proceedings on National Workshop on Quality Education and Future Directions to Ethiopia. A.A, Ethiopia, PP,26-86, 113.

Wang, M. (2009). Effects of Metacognitive Reading Strategy Instruction on EFL High School Students' Reading Comprehension, Reading Strategies Awareness and Reading Motivation. (Doctor of Philosophy Dissertation), University of Florida.(Pp.19-34).

Wiggins, G. \& McTigle, J., (2005). Understanding by Design, $\left(2^{\text {nd }}\right.$ Ed. $)$. ASCD: Washington DC. (Pp.239). 
Williams, Riama Shiri, Omer Ari, \& Santamaria, Carmen Nicole. (2011). "Measuring College Students' Reading Comprehension Ability Using Cloze Tests," Journal of Research in Reading 34 (2): 215-231. 